\title{
Monseñor Miguel Ángel Builes, un político intransigente y escatológico (1925-1950)*
}

\section{Resumen}

En este artículo se describe la relación existente entre los partidos políticos y el catolicismo en Colombia por medio del análisis de las cartas pastorales de Monseñor Ángel Builes. Un ejemplo de como la pareja política-religión marcó la cultura y la historia política colombiana y contribuyó a crear una sociedad de tipo confesional y tradicionalista. En este sentido, el caso de Monseñor Builes es uno de los más representativos, dada su intransigencia y sus críticas escatológicas a cualquier vestigio de secularización de la sociedad; de ahí que en esta ocasión se estudie su pensamiento político a la luz de los nuevos aportes historiográficos, que en los últimos años han buscado explicar la relación entre religión-política. Además, se ha escogido a Monseñor Builes para explicar desde una región (Antioquia) y con un personaje en particular cómo se dio el proceso de confesionalización de la sociedad colombiana en el final de la Hegemonía Conservadora y la reacción tradicionalista frente a los intentos laicistas de los liberales, durante la República Liberal (1930-1946).

Palabras clave: Colombia, catolicismo, intransigencia, escatología, cultura, política.

Referencia para citar este artículo: FIGUEROA SALAMANCA, Helwar H. (2016). "Monseñor Miguel Ángel Builes, un político intransigente y escatológico (1925-1950)", en Anuario de Historia Regional y de las Fronteras, 21 (1). pp. 237-259.

Helwar Hernando Figueroa Salamanca: Doctor en Estudios Latinoamericanos de la Universidad de Toulouse Le Mirail, Francia. Magíster en Historia. Historiador de la Universidad Nacional de Colombia. Miembro del grupo de investigación sobre el hecho religioso: Sagrado y Profano. Profesor asociado de la Universidad Industrial de Santander, UIS. Correo electrónico: helwarff@uis.edu.co.

\footnotetext{
* Artículo resultado de investigación.
} 


\title{
Monsignor Miguel Ángel Builes, an Intransigent and Eschatological Politician (1925-1950)
}

\begin{abstract}
This article describes the relation between political parties and Catholicism in Colombia by analyzing the pastoral letters written by Monsignor Angel Builes. This relation represents a highlight for the culture and political history of Colombia since it contributed to the creation of a confessional and traditionalist society. Monsignor Builes case is one of the most paradigmatic examples of this relation due to his intransigency eschatology and criticism toward any trace of secularization of society or laicization of the State. Besides, his thought oriented a vast section of the public opinion of his time. His political thought is analyzed based on new historiographical contributions whose objective is to explain the relation between religion and politics. Furthermore, the person of Monsignor Builes was chosen in order to illustrate how this confessional process occurred from one region (Antioquia) and permeated the Colombian society at the end of the Conservative Hegemony, including the posterior conservative and clerical reaction, as opposed to the secularization attempts made during the Liberal Republic (1930-1946).
\end{abstract}

Keywords: Colombia, catholicism, intransigency, eschatology, culture, politics.

\section{Monsenhor Miguel Ángel Builes, um político intransigente e escatológica (1925-1950)}

\section{Resumo}

Neste artigo se descreve a relação existente entre os partidos politicos e o catolicismo na Colômbia por meio da análise das cartas pastorais do Monsenhor Miguel Ángel Builes. Uma relação que marcou a cultura e a história política colombiana e que contribuiu para a criação de uma sociedade do tipo confessional e tradicionalista. O caso do Monsenhor Builes é um dos exemplos mais paradigmáticos nesse sentido, porque sua intransigência e suas críticas escatológicas a qualquer vestígio de secularização da sociedade ou de laicização do Estado orientaram grande parte da opinião pública de seu tempo; daí que nessa ocasião se estude seu pensamento político em face das novas contribuições historiográficas, que nos últimos anos tem buscado explicar a relação entre religião e política. Além disso, o Monsenhor Builes foi escolhido para se explicar, a partir de uma região (Antioquia) e com um personagem em particular, como se deu o processo de confessionalização da sociedade colombiana ao final da Hegemonia Conservadora, e a posterior reação conservadora e clerical frente as tentativas laicistas dos liberais durante a República Liberal (1930-1946).

Palavras-chave: Colômbia, catolicismo, intransigência, confessionalização, cultura, política. 


\section{Introducción}

La relación entre los partidos políticos y el catolicismo selló la cultura y la historia política colombiana y contribuyó a crear una sociedad de tipo confesional y tradicionalista, que solo hasta bien entrado siglo XX le abrió las puertas a la separación Iglesia-Estado. En efecto, en Colombia la tradicional jerarquización de la sociedad, el tradicionalismo cultural y el conservatismo político ${ }^{1}$ de sus elites y las dificultades para que los movimientos sociales y culturales logren afianzarse, evidencian una sociedad en la cual la secularización cultural y la laicización del Estado no lograron desarrollarse plenamente.

Por tal motivo, es evidente que desde su constitución como República, las oligarquías han visto en la institución eclesiástica una herramienta de control social, afín a un modo conservadurista de pensar la sociedad; un catolicismo, en su vertiente intransigente, que se resiste a desaparecer y que en las múltiples guerras civiles se muestra como la mejor arma ideológica a la hora de deslegitimar al adversario político. Por cierto, una utilización maniquea efectiva, gracias al peso de lo político, dado que en Colombia durante gran parte de su vida republicana se privilegió la adscripción partidista por encima de cualquier referente nacionalista. De esta manera, los conservadores se asociaban a la institución católica para generar cierta gobernabilidad en los períodos en que se encontraban en el poder, ante lo cual los liberales reaccionaron, a mediados del siglo XIX y en la década de 1930, separando la Iglesia del Estado, para luego nuevamente ser contra-reformada por los conservadores en 1886 y en la década de 1950; ratificándose esta unión por medio de la re-consagración del país al Sagrado Corazón en 1952, y en 1957, plebiscitariamente.

El caso de Monseñor Miguel Ángel Builes es uno de los ejemplos más paradigmáticos en la relación política-religión, dada su intransigencia y críticas a cualquier vestigio de secularización de la sociedad o separación de potestades; de ahí que en esta ocasión se estudie su influencia política de 1925 a 1950. Un periodo en el cual los liberales vuelven a intentar poner en práctica la separación IglesiaEstado -luego de que en 1929, la división de los conservadores acabara con su hegemonía política que les había permitido gobernar desde 1886-. Por cierto, al lado de Monseñor Builes, para la época de su influencia existen otros personajes religiosos que con su pensamiento político y actuar religioso contribuyeron a polarizar los enfrentamientos partidistas. Así tenemos al sacerdote Cayo Leónidas Peñuela y Fray Mora Díaz en Boyacá y a Daniel Jordán en los dos santanderes, por solo mencionar a los más representativos.

\footnotetext{
${ }^{1}$ La diferencia entre el tradicionalismo (categoría histórica universal que hace referencia al interés de mantener vigente la cultura heredada, en oposición a la modernidad) y el pensamiento conservadurista (un orden social y político soportado en instituciones jerárquicas, en respuesta a la Revolución Francesa) permitiría concluir que en Colombia la cercanía de los conservadores con la jerarquía eclesiástica creó una idea de sociedad conservadora y tradicional, de talante nacionalista y católica. Pérez Rivera, Eduardo. "El nacionalismo católico colombiano: un estilo de pensamiento (1870-1946), en Nación y nacionalismo en América Latina (Bogotá: CES-FLACSO), pp. 125-152.
} 
En efecto, durante la República Liberal (1930-1946), Monseñor Miguel Ángel Builes fue uno de los personajes más destacados de la política antioqueña ya que lideró una de las más sistemáticas campañas clericales en contra del Partido Liberal. Las pastorales que publicó desde su primer año como obispo de Santa Rosa de Osos (1924) fueron de las más divulgadas y comentadas. Están escritas en tono escatológico, moralizante, dogmático y antiliberal, y constituyen uno de los ejemplos más intransigentes de un sector del clero. En este caso, del clero rural, particularmente antioqueño, considerado por la historiografía colombiana como uno de los más conservadores del país ${ }^{2}$.

Por último, esta propuesta metodológica y teórica podría considerarse como revisionista, ya que se realiza a la luz de los nuevos aportes historiográficos que en los últimos años han buscado explicar la relación entre religión-política y que intentan superar la historiografia liberal que desconocía cualquier contribución de la institución eclesiástica para crear nación o la conservadora, evidentemente, de talante panegírica ${ }^{3}$. Se ha escogido a Monseñor Builes para explicar cómo desde una región (Antioquia) y con un personaje en particular se dio el proceso de confesionalización de la sociedad colombiana durante la Hegemonía Conservadora (1886-1930) y los intentos por mantener este orden en los primeros años de la República Liberal (1930-1946). Un actor político religioso que basaba su discurso mostrando a los liberales como ateos, y a la modernidad como un invento anticristiano, en un momento en la que la Iglesia Católica comenzaba a ver en los protestantes y en los pocos comunistas del país a sus principales enemigos ${ }^{4}$; y que Monseñor Builes solo identifica como personajes, que a pesar de estas vestiduras, en el fondo seguían siendo liberales. En este escenario, los sectores más tradicionalistas de la Iglesia, junto con el Partido Conservador, proponían el confesionalismo como el mejor modelo de sociedad; el hispanismo como una propuesta cultural adecuada para hacerle frente al panamericanismo; y el corporativismo (vía la Encíclica Quadragessimo Anno) como la opción económica

\footnotetext{
${ }^{2}$ Londoño Vega, Patricia. Religión, cultura y sociedad en Colombia. Medellín y Antioquia, 1850-1930 (Bogotá: FCE, 2004).

${ }^{3}$ Para un estudio más detallado de la historiografía sobre la Iglesia Católica en Colombia y que da cuenta de los avances académicos se pueden consultar cinco balances historiográficos elaborados en diferentes contextos y períodos: Grupo de Investigación Religión, Cultura y Sociedad (GIRCS). Historiografia sobre religión, cultura y sociedad en Colombia producida entre 1995 y el 2000 (Medellín: Universidad Nacional de Colombia, 2001); Arias, Ricardo. "La historiografía de la Iglesia católica en Colombia", en Bonnet, Diana y Maya, Luz Adriana (comps.), Balance y desafios de la historia de Colombia al inicio del siglo XXI (Bogotá: Universidad de los Andes, 2003); Cortés, José David. "Balance bibliográfico sobre la historia de la Iglesia católica en Colombia, 1945-1995”, en Historia Crítica, n. ${ }^{\circ}$ 12, 2006, pp. 3-12; Plata, William Elvis. "Entre la teología y las ciencias sociales. Tendencias de la historiografía de la Iglesia Católica en Colombia, en el contexto latinoamericano", en González, Andrés Eduardo (comp.), Diversidad y dinámicas del cristianismo en América Latina. Memorias del primer congreso internacional (Bogotá: Universidad de San Buenaventura), pp.107-148; y Cortés, José David. "Balance historiográfico sobre las relaciones

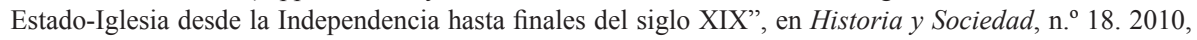
pp. 163-190.

${ }^{4}$ Figueroa Salamanca, Helwar H. "Historiografía sobre el protestantismo en Colombia. Un estado del arte, 1940-2009", en Anuario Colombiano de Historia Social y de la Cultura, n. ${ }^{\circ}$ 37, 2010, pp. 191-225. Y Figueroa Salamanca, Helwar H. "Cambio de enemigo: de liberales a comunistas. Religión y política en Colombia, años cuarenta”, en Bidegain Greising, Ana María y Demera, Juan Diego (comps.), Globalización y diversidad religiosa en Colombia (Bogotá: Universidad Nacional de Colombia, 2005), pp. 167-196.
} 
más idónea ante el capitalismo y al socialismo económico ${ }^{5}$. Un programa que para Builes no era pertinente, puesto que su formación teológica y convicciones políticas lo identificaban más con el neotomismo y la intransigencia de Pío IX que veía en la crítica al liberalismo como su principal arma política.

\section{La formación de un intransigente}

Monseñor Builes nació el 9 de septiembre de 1888 en Donmatías, Antioquia. Recibió su ordenación en 1914 y fue nombrado tempranamente obispo de la Diócesis de Santa Rosa de Osos en 1923. La personalidad de Builes, según uno de sus principales biógrafos, estuvo marcada por su odio al liberalismo. Desde sus primeras intervenciones públicas como prelado, los anatemas que escribía iban dirigidos directamente contra el liberalismo. En Remedios, pueblo donde ejerció por primera vez funciones como párroco en propiedad, en el año de 1921, sufrió un atentado a manos de los liberales. Este incidente es considerado por sus biógrafos como uno de los motivos más significativos para que Builes odiara al Partido Liberal. Aunque también su formación apologética jugó un papel importante a la hora de justificar su intransigencia. Ciertamente, en los años en que Builes se formaba como sacerdote, en los seminarios estaba en boga y un tanto anacrónicamente la teología escolástica y el neotomismo. Dos de sus principales divulgadores, monseñor Tomas María Carrasquilla (1858-1940) y el canónigo Cayo Leónidas Peñuela (1875-1945), veían en la modernidad el mayor enemigo de la Iglesia. Como lo había estipulado en el siglo XIX el Papa Pío IX en la Encíclica Quanta Cura y su anexo el Syllabus (1864), donde hace un listado de los errores de la modernidad y el liberalismo y se invita a defender intransigentemente el catolicismo. Además, en la década de 1920, la máxima autoridad jerárquica del país, el Primado de Colombia, Bernardo Herrera Restrepo (1902-1928), tenía tal poder que durante gran parte de la Hegemonía Conservadora (1886-1930) fue el encargado de avalar a los presidentes conservadores, estigmatizando de paso a los liberales, lo cual hacía que toda la clerecía desde muy temprano se identificara con las ideas de sus copartidarios, los conservadores ${ }^{6}$. La intransigencia católica y el conservatismo de estos años son afines, por lo tanto su enemigo es el mismo, los liberales; a pesar de que estos buscaban demostrar por todos los medios posibles que el liberalismo colombiano no era contrario a la fe cristiana, como lo hizo Rafael Uribe Uribe en $1912^{7}$.

El periodista e historiador Miguel Zapata Restrepo considera que la personalidad impulsiva y panfletaria de monseñor Builes, que por momentos era evidente en sus intervenciones pastorales, se podría explicar por la escasa experiencia que tuvo como sacerdote y por su temprano nombramiento como obispo, a la edad de 36 años ${ }^{8}$. Sin

\footnotetext{
${ }^{5}$ Figueroa Salamanca, Helwar H. Tradicionalismo, hispanismo y corporativismo. Una aproximación a las relaciones nos sanctas entre religión y política (1930-1952) (Bogotá : Universidad de San Buenaventura, 2009).

${ }^{6}$ Abel, Christopher. Política, Iglesia y Partidos en Colombia 1886-1955 (Bogotá: FAES, Universidad Nacional de Colombia, 1987).

${ }^{7}$ Uribe Uribe, Rafael. El liberalismo colombiano no es pecado. (Planeta: Bogotá, 1995).

${ }^{8}$ Zapata Restrepo, Miguel. La Mitra Azul. Miguel Ángel Builes: el hombre, el obispo, el caudillo (Medellín: Beta, 1973).
} 
embargo, resulta más apropiado, para intentar dar una explicación más sociológica, considerar que las posiciones políticas de Builes fueron producto del contexto en que vivió y se formó como clérigo. En efecto, al hacer un seguimiento de otros clérigos $^{9}$ que escribieron por aquella época es posible observar similitudes en sus planteamientos, los cuales obedecen claramente a orientaciones institucionales de unos de los sectores que más ha logrado incidir en la institución clerical colombiana y que como se ha afirmado hunde sus raíces en el siglo XIX, los llamados intransigentes. Es así como desde su primera pastoral, al tomar posesión de la Diócesis de Santa Rosa de Osos (22 de octubre de 1924), Builes pone en evidencia su lenguaje moralista e intransigente, inspirado en la orientación del Vaticano. Ahora bien, en este primer discurso episcopal sobresale su convicción de que su labor como obispo es vigilar la moral de sus feligreses; entre otras, unas de las funciones más claras que realizan los obispos dentro de la estructura clerical. El lenguaje basado en la teología moral lo caracterizará durante toda su vida pública.

Soy vuestro Padre, hermanos míos; pero por lo mismo que el padre es por imposición misma de la naturaleza maestro y guía de sus hijos, heme aquí como doctor y guía de vuestras almas. La misión que el cielo me ha confiado a este respecto es muy sublime: enseñaros y amar a Dios $[\ldots]$

Pero, si vengo como maestro a enseñaros la verdad, es preciso que para cumplir este cargo os señale también el error. Los días que alcanzamos son de confusión de ideas en los espíritus y de revuelta de sentimientos en los corazones. Una nube oscura cargada de tempestad se cierne sobre la Barca de Pedro que es la Iglesia de Cristo, y amenaza hundirla en las lobregueces de este océano de pasiones en que se agita el mundo. El Obispo a manera de Faro luminoso debe derramar sus destellos señalando los errores que como escollos y como abismos amenazan vuestra fe, vuestra religiosidad y la vida divina de vuestras almas [...]

Fijad los ojos en vuestro Obispo y seguid el derrotero que os señale para que os veáis libres de los errores, las sectas y la herejía de estos días malos ${ }^{10}$.

Según Rafael Tamayo desde finales del siglo XIX el discurso religioso puede caracterizarse por su fuerte componente apocalíptico donde el pecado, el purgatorio y el infierno son las armas esgrimidas para atacar a los liberales ${ }^{11}$. En este fragmento, característico de Builes, la tempestad de pasiones que amenaza a la Iglesia Católica evidentemente está representada en los errores y la herejía desatada por un liberalismo cada vez que llegan al poder, que por aquello años comienzan a liberarse del dominio conservador y católico. Un liberalismo que metafóricamente había sido castigado, recluyéndolo en las cavernas de satán y que empezaba a levantar cabeza.

\footnotetext{
${ }^{9}$ Fray Ezequiel Moreno, Monseñor Thomas Carrasquilla, Cayo Leónidas Peñuela, Daniel Jordán, Fray Mora Díaz y Juan Manuel Arbeláez, entre los más prominentes durante la primera mitad del siglo XX.

${ }^{10}$ Builes, Miguel Ángel. "Saludo en la toma de posesión de la Diócesis, el 22 de octubre de 1924, al venerable clero y a los fieles", en Cartas Pastorales. 1914-1939 (Medellín: Imprenta Editorial, 1939), pp.10-13. Cursiva de la investigación.

${ }^{11}$ Tamayo Franco, Rafael. Los discursos de la escatología católica en los imaginarios religiosos y políticos, Colombia 1887-1965, (Tesis doctoral), Universidad Nacional de Colombia, 2015.
} 
Desde 1924 hasta el año de 1967 monseñor Builes en sus pastorales no dejó de utilizar este lenguaje moralista y escatológico que tal vez lograba penetrar con fuerza en las ideas y actuaciones de los creyentes. Estaba convencido de que la Iglesia Católica era la única institución a la cual le estaba permitido velar por la moral y las creencias de los colombianos. Una idea que para la época todavía resulta totalmente vigente puesto que el peso de una clerecía predominantemente rural se mostraba como la única institución capaz de ser una guía en medio de la vida campesina. Esta idea también provenía del papel protagónico que tenía la institución eclesiástica en el mundo de la política desde la Constitución de 1886 y de la cual fue uno de sus principales adalides. Según se percibe en las diferentes publicaciones de la época y lo referido por los historiadores, las pastorales de monseñor Builes eran esperadas con ansiedad para ser leídas en los púlpitos y reproducirlas en periódicos y volantes de todo el país; esto con el objeto de atizar el fuego en época de elecciones o de confrontación partidista. Los liberales las usaban para acusar al clero de ser intransigente e inmiscuirse en política y los conservadores para recordarles a los liberales que Dios estaba del lado conservador.

Fueron tan importantes para Builes sus cartas pastorales que al ser entrevistado por el periodista Miguel Zapata Restrepo sobre el significado de aquellas fue contundente en afirmar:

-De mí se dicen exageraciones y se me atribuyen sermones que no he pronunciado. Mi pensamiento aparece claro, diáfano, en las cartas pastorales. Cada una de ellas corresponde a una exigencia. Lea esos documentos. En ellos encontrará la biografía exacta del Obispo Builes. La personalidad de Miguel Ángel Builes, nacido en Donmatías, no tiene importancia para nadie. Cuando me consagraron, dejé atrás los detalles insignificantes. Como jerarca católico he actuado por más de un cuarto de siglo. Por ese concepto me place ser juzgado ${ }^{12}$.

Leyendo, una a una, las pastorales de Builes, la mayoría escritas para ser leídas durante la Cuaresma, es evidente que sus orientaciones mantienen el mismo esquema y son recurrentes en su contenido escatológico. Con el objeto de comprender cuáles eras sus justificaciones teológicas y políticas y por considerar que su pensamiento refleja el ala más intransigente del clero en Colombia y, particularmente, del departamento de Antioquia, a continuación se hará un recuento y análisis de sus pastorales más significativas. De su primera pastoral de 1924, después de argumentar sobre la autoridad de los obispos como representantes de Jesucristo en la Tierra, sobresale la siguiente justificación sobre su función como líder espiritual:

¿Para qué ha dotado Dios al Obispo de tan admirables prerrogativas, de tan sublimes poderes? Ah! Carísimos hermanos: estas prerrogativas son deberes por cuanto el episcopado, como el sacerdocio, es una gracia gratis data, es decir, para el bien de los demás. Sí, la autoridad espiritual no es un patrimonio del que la recibe, no es un bien suyo propio, no puede usar de ella en propia y exclusiva utilidad. Ved si no a nuestro Santo Padre el Papa: goza del glorioso privilegio de la infalibilidad en materia de fe y de costumbres; ¿pero esta prerrogativa

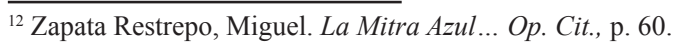


le sirve acaso para su propio provecho? No: es para vosotros solos, carísimos hermanos, para vosotros que necesitáis conocer la verdad divina. ¿De qué le sirve a él la asistencia del Espíritu Santo en sus definiciones? ¿Recibe con ésta la infalibilidad papal en su conducta? ¿Se acaban para él los trabajos, las fatigas y las penas? [...] No, hermanos carísimos: el Sumo Pontífice no es más que un oráculo a favor del pueblo cristiano, que lleva sobre sus hombros la inmensa responsabilidad del más elevado cargo, que tiene la obligación de responder a los mil intrincados problemas que interesan a la humanidad entera $[\ldots]^{13}$.

La pastoral continúa describiendo y justificando la autoridad de los obispos sobre el clero y sus feligreses; para ello recurre a las encíclicas papales, a los padres de la Iglesia y a la Biblia; fuentes en las cuales se da doctrina sobre esta materia. Builes culmina su declaratoria, reconociendo la labor de las Misioneras de María Inmaculada, de los hermanos lasallistas, de las capuchinas y de la hermanas de la Presentación, para terminar consagrando su misión episcopal a la Virgen María. Esta pastoral será una de las más piadosas y de las pocas en las cuales las referencias directas a la política fueron casi nulas, no obstante desde sí se estudian teológicamente el lector se sorprenderá al descubrir en ellas decenas de metáforas escatológicas que nos hablan del pecado liberal y del infierno del que no deben salir.

\section{El socialismo, un enemigo en formación}

En los años veinte, a pesar de la hegemonía conservadora y confesional o tal vez como respuesta a ella, los movimientos sociales se radicalizaron en sus manifestaciones políticas. Por aquellos años, las ideas socialistas acompañan a los nacientes movimientos sociales que comienzan a desplazar las manifestaciones de los artesanos. Así un incipiente movimiento campesino, estudiantil y obrero comienza a ocupar las páginas de los periódicos y a preocupar al establecimiento que por medio de leyes y acciones policivas reprime dichas manifestaciones. Ante lo cual los sectores tradicionales de la sociedad responden afirmativamente.

En la pastoral del 2 de febrero de 1926, Builes sienta cátedra sobre el socialismo y define cuál será su posición frente a este; además, recordando que Colombia está consagrada al Sagrado Corazón de Jesús, insiste en que el país está protegido ante las sectas y el bolchevismo de Lenin. No obstante, recuerda a su feligresía que estas ideas ocasionaron que en Rusia mataran 28 obispos y 1.315 sacerdotes, según cifras de la Revue de Deux Mondes. Argumento al cual recurrirá durante toda su vida y al cual sumará las persecuciones que se estaban comenzando a sufrir los clérigos en México y en España. En la argumentación sobre qué es el socialismo, Builes realiza una mezcla confusa de tradiciones y culturas, con el propósito de mostrar que el socialismo es de origen pagano. Según él, en Grecia, en Egipto y en el imperio Inca hubo expresiones de socialismo. Los precursores del racionalismo, Kant, Hegel y Rousseau, también fueron los antecedentes teóricos del socialismo, convertido en comunismo por la mano de Marx. Builes considera que Marx —basado en una falsa premisa sobre el

\footnotetext{
${ }^{13}$ Builes, Miguel Ángel. "Primera carta pastoral al clero y fieles de su Diócesis", octubre 22 de 1924, en Cartas Pastorales... Op. Cit., pp. 30 y 31.
} 
derecho que tienen los obreros a la propiedad derivada de su trabajo - induce a los obreros a la revolución:

Pobres nuestros obreros quienes halagados con falsas promesas de redención que dizque les van a dar sus falsos profetas, sus fementidos libertadores, ayudan eficazmente a que todos los bienes de los particulares pasen al Estado para que este los reparta por igual a los hombres laboriosos y holgazanes; a los que producen riqueza con su trabajo y a los que como parásitos chupadores consumen, pero no quieren trabajar [...] Lo que Dios hizo desigual, el hombre no puede cambiarlo, y el derecho de propiedad que nace con el hombre, no podrán destruirlo todos los socialistas del mundo. Podrá aniquilarse la humanidad como en parte aconteció en Rusia; pero el derecho natural no se destruirá jamás ${ }^{14}$.

Después de estos argumentos de tipo intelectual recurre al que él considera es el más importante de los errores del socialismo: su condición irreligiosa e inmoral. "Es irreligioso —escribe Builes- porque para él no hay Dios, y esta negación de la Divinidad la declara rabia infernal y con blasfemias horribles. Para él no hay superiores en el orden espiritual ni representantes de Dios, y de allí su odio innato a la sotana, que por sí sola reprocha su maldad; para él no hay nada santo, no hay nada sagrado" 15 . Ser socialista es entregarse al demonio, personificado en Marx y sus doctrinas ateas. Aquí es evidente como su escatología logra su coherencia interna apelando al infierno, el mejor argumento de la época, que como nos lo demuestra Tamayo, logra su mayor desarrollo precisamente en el período en que Builes adquiría sus mejores armas teológicas, las emanadas oficialmente de la Iglesia colombiana:

En Colombia a finales del siglo XIX, la base discursiva de la iglesia se construyó desde la noción de obediencia, única forma de mantener el orden y evitar el caos. La obediencia se predicaba tanto por vía positiva (lo que hay que hacer para salvarse), como por vía negativa (lo que no hay que hacer para evitar condenarse). Los dos principales ámbitos de los discursos eclesiales sobre el purgatorio y el infierno fueron por una parte la educación religiosa y catequética, normalmente en la escuela; y por otra parte la predicación en el templo. Desde muy temprano la vida de los creyentes entraba en contacto con las representaciones de la escatología de castigo, las cuales estarían presentes durante toda la vida ${ }^{16}$.

Tamayo en sus investigaciones teológicas sobre la relación política-religión en Colombia es claro en señalar, desde el comienzo, que no deberíamos sorprendernos sobre la cercanía o interrelación de este dúo ideológico, pues toda teología es política. Además, recurriendo a Foucault argumenta que esta sintonía logra incidir con más vehemencia en el imaginario de los creyentes, es un dispositivo de control social efectivo.

\footnotetext{
${ }^{14}$ Builes, Miguel Ángel. "El socialismo", febrero 2 de 1926, en Cartas Pastorales... Op. Cit., p. 75.

${ }^{15}$ Ibid., p. 78.

${ }^{16}$ Tamayo Franco, Rafael. "Los imaginarios del purgatorio y el infierno durante la primera mitad del siglo XX en Colombia, entre la política y la religión". Ponencia presentada en el XVII Congreso Colombiano de Historia, Bogotá, octubre 5-10 de 2015.
} 


\section{El problema religioso y la revolución}

La pastoral que aborda directamente el problema religioso será la del año siguiente. En esta pastoral Builes vincula la Revolución Rusa con la mexicana para mostrar el peligro latente que existe para la Iglesia si el socialismo logra crecer en el país, de la mano de los liberales. En ella expresa los siguientes argumentos: 1) las mujeres están comenzado a seguir modas pecaminosas en su vestir; 2) en los confesionarios hay menos jóvenes expiando sus culpas; 3) las doncellas cada vez son menos dóciles; 4) los campesinos se están levantando frente a sus amos; 5) el aumento de la violencia en el campo; 6) los periódicos están llenos de blasfemias en contra de la Iglesia y el orden conservador; 7) hay brotes de subversión obrera; 8) se están incrementado las huelgas; 9) y, por último, se está creando un movimiento socialista que amenaza con hacer la revolución en Colombia. En efecto, afirma que "Todo esto significa que hay gérmenes de descomposición moral y social muy desarrollados y que nos amenazan por consiguiente días de lágrimas y sangre como los de Rusia y México [...]"17.

Las referencias a las revoluciones (liberales y socialistas) serán una constante en la literatura político-religiosa de la primera mitad del siglo XX pues era los ejemplos más adecuados para defender la presencia de la institución eclesiástica ante los intentos liberales de romper los fuertes vínculos entre esta y el Estado conservador. Además, en el análisis que hace sobre los peligros de la Iglesia y el orden conservador resalta cómo las mujeres y los jóvenes comienzan a distanciarse el dominio confesional, las primeras cambiando sus costumbres en el vestir y los segundos, dejando de asistir al templo y a la confesión. La huelga y el levantamiento de los obreros y de los campesinos ante sus "amos" para Builes son la prueba fehaciente de que la revolución socialista se está acercando y amenaza con destruir el orden católico. Cuando Builes era testigo del incremento de las luchas sociales que se dieron con beligerancia en de la década de 1920 y de las cuales da cuenta el beligerante historiador e intelectual Renán Vega en su magnífica obra Gente muy Rebelde.

\section{La ciudad, "un antro de perdición"}

Una de las pastorales por la cual monseñor Miguel Ángel Builes es uno de los obispos más recordados está relacionada con su postura frente al progreso que según él viene con el ferrocarril. En este caso, el ferrocarril representa para las provincias rurales la llegada de los lupanares, el trago, la vida alegre y la irreligiosidad. La Iglesia deja de ser el centro de la vida social y comienza a ser desplazada por otras sociabilidades. Builes se lamenta de los esfuerzos perdidos en la formación religiosa de los campesinos, cuando son atrapados por la vida libertina que acompaña el progreso. "El progreso debe ser armónico en lo material - escribe- y en lo espiritual, sin que el brillo de los focos eléctricos ni los maravillosos descubrimientos modernos, apaguen la luz sobrenatural; sin que el ruido de los trenes, los aviones y los autos, cierren nuestros oídos a la voz de Dios"18. Le preocupa ingenua o piadosamente que el progreso del

\footnotetext{
${ }^{17}$ Builes, Miguel Ángel. "El laicismo", febrero 2 de 1927, en Cartas Pastorales... Op. Cit., p. 113.

${ }^{18}$ Builes, Miguel Ángel. "Los peligros del progreso", febrero 2 de 1929, en Cartas Pastorales... Op. Cit., p. 140.
} 
hombre no esté a la par del progreso espiritual. La visión negativa que tiene del progreso, la explica de forma maniquea, pues según su lógica equivale al naturalismo, al racionalismo, al materialismo y al liberalismo; doctrinas condenadas por la Iglesia decimonónica.

En efecto, el progreso simbolizado en algunas manifestaciones materiales preocupa a Builes, quien es consciente que con la inevitable entrada de la modernización a la sociedad dificultará la labor pastoril pues las que él llama distracciones comenzarán poco a poco a ser mella en las tradiciones de los colombianos, que por aquellos años todavía encuentran en la asistencia al templo un escenario no solo de recogimiento espiritual sino de lugar de encuentro. Para él con las carreteras llega el progreso acompañado de los lupanares, la perdición y la fractura de la familia:

Nuestra amada Diócesis se cruza de carreteras que con el ferrocarril troncal de Occidente le abren un risueño porvenir; pero esas mismas obras de progreso le están haciendo sufrir un espantoso retroceso espiritual que nos tiene alarmados gravemente $[\ldots]$ ¿Habéis visto esa multitud de hombres que trabajan en las carreteras? La mayor parte de ellos son víctimas del ambiente que en esos lugares se respira. Olvido de Dios, desprecio de los días Santos, bailes, juegos, licores, gestos abominables, sonrisas que denuncian liviandad, molicie pavorosa, fornicación, adulterios, pensamientos lúbricos, deseos pecaminosos, es la carroza de Asmodeo, el demonio de la impureza, que arrastra una inmensidad de pueblos. De allí vienen los hombres casados sin amor al hogar, y los jóvenes marchitos en flor. Pobre esposa, pobres hijos: no pensaron que su esposo y padre iba a sucumbir en la banca o en la vía férrea al impulso del ambiente: pobre sociedad futura si los jóvenes pierden en la carretera con la inocencia conservada en la montaña, la fuerza vital que asegura el porvenir de la raza y de la humanidad ${ }^{19}$.

La carroza de Asmodeo que arrastra el progreso y sus maldades evidentemente es el ferrocarril. Una de los principales símbolos de los avances técnicos presentes en la Revolución Industrial. Builes era consciente de sus palabras, sabía lo que significó para Europa el avance de la técnica que proporcionalmente ocasionaba la pérdida del predominio católico. En esta pastoral se ve una vez más las referencias al infierno y el castigo, en una defensa acérrima de las buenas costumbres y la vida en familia. Llama la atención el significado identitario que le da a la montaña, la que forja el espíritu, las alusiones son innegables a la antioqueñidad, a la tozudez del montañero y sus convicciones católicas. Es la oposición del mundo de las tierras bajas y calientes del Ferrocarril de Occidente, rodeo de la presencia del demonio y de la ausencia de Dios. La montaña es sagrada, los ríos o valles de las zonas bajas, calientes, lúbricas son pecadoras. La salvación está en la montaña, el infierno, abajo.

El historiador Rodolfo de Roux además es más radical en su crítica de la incapacidad de la Iglesia para adaptarse a los nuevos tiempos y nos recuerda como un año después de la pastoral de Builes, el alto clero en acuerdo consideran que la vida del campo y de la montaña es tranquilizador para el espíritu. La Pastoral Colectiva de 1930,

${ }^{19}$ Ibid. 
dirigida a los campesinos, los invita a mantenerse en el campo, pero esta vez son más vehementes y claros en sus temores a la ciudad y el progreso, donde no solo hay lupanares, hay ideas que invitan a la revolución: "No os dejéis trastornar la cabeza por las doctrinas de propaganda socialistas y bolcheviques, quienes solo quieren pervertir vuestra conciencia [...] Conservad firme la fe de vuestros abuelos y la paz bendita que el cielo os ha dado por herencia"20.

\section{El liberalismo es pecado}

Pero va a hacer la pastoral de 1931 la que lo consagrará a Builes como uno de los obispos más intransigentes en contra del liberalismo. El contexto de esta pastoral fue la llegada a la presidencia del liberal Enrique Olaya Herrera (1930-1934), quien propuso un gobierno de "Concentración Nacional" con la participación de liberales y conservadores. Con el gobierno de Olaya Herrera comenzó el período conocido como la República Liberal (1930-1946). Como era de esperarse, la reacción de Builes fue categórica, volvió a la arena pública con unas de sus pastorales más intransigentes y que en ese momento nadie esperaba, pues los máximos jerarcas de la Iglesia, encabezados por Monseñor Ismael Perdomo, reconocieron con entusiasmo la presidencia de Olaya Herrera, quien proponía un gobierno de transición y por encima de los partidos; es decir, de tipo nacionalista. El clero de provincia no asumió esta actitud conciliadora; clérigos como Cayo Leónidas Peñuela, Fray Mora Díaz, Daniel Jordán y el propio Builes fueron al ataque. La intransigencia resurgía ${ }^{21}$ como una corriente importante dentro del clero que se negaba a perder el poder que la Iglesia había adquirido durante la Hegemonía Conservadora (1886-1930).

Que el liberalismo ya no es pecado, se viene diciendo últimamente con grande insistencia; que los prelados no solo callan sino que han prohibido hablar del liberalismo; que se levantó la censura de algunos periódicos liberales; que el Papa dirigió una carta laudatoria al Excelentísimo Señor Presidente, y que por lo tanto ser liberal ya no es malo: en una palabra que se pueden seguir tranquilamente sin gravamen y conciencia las doctrinas del liberalismo y que se puede votar sin pecado por candidatos liberales, sin que eso sea obstáculo para recibir la absolución y participar de todos los bienes y derechos de la Iglesia.

Nada más erróneo, pues lo que es esencialmente malo jamás dejará de serlo, y el liberalismo es esencialmente malo $[\ldots]^{22}$.

Frente a la actitud asumida por los altos jerarcas de Bogotá en 1930, quienes predicaban el respeto a las autoridades legítimamente constituidas, Builes asume la vocería de los sectores que no estaban dispuestos a obedecer las orientaciones del Primado de Colombia, Monseñor Ismael Perdomo. Después de que en su pastoral hacía evidente esta posición, pasó a justificar por qué el liberalismo es pecado y para ello basó sus argumentos en un extenso número de críticos del liberalismo, comenzando por las declaraciones pontificias de Pío IX y León XIII, para después recurrir a infinidad

\footnotetext{
${ }^{20}$ Citado por de Roux, Rodolfo. Una iglesia en estado de alerta. (Bogotá: Guadalupe, 1983), p. 54.

${ }^{21}$ Figueroa Salamanca, Helwar H. Tradicionalismo, hispanismo y corporativismo... Op. Cit.

${ }^{22}$ Builes, Miguel Ángel. "El liberalismo”, abril 5 de 1931, en Cartas Pastorales... Op. Cit., p. 190.
} 
de autores católicos. Para la Iglesia ser liberal era ir en contra de la religión. Liberal era sinónimo de ateo y enemigo del cristianismo por tal motivo su único destino es el infierno. Su escatología sobre el pecado, el infierno y el castigo durante estos años será su mayor argumento para atacar a los liberales ${ }^{23}$. Al explicar por qué los católicos no pueden ser liberales, Builes afirma que el agua no se puede mezclar con el aceite, la luz con las tinieblas. Posteriormente, hace un recuento histórico de todas las atrocidades de que fue víctima la institución eclesiástica en Colombia a manos de los liberales. Para culminar invitando a sus feligreses a votar por candidatos afines a la Iglesia: “[...] amados hermanos e hijos nuestros tenéis la obligación de dar vuestros votos en las elecciones según vuestra conciencia y por candidatos católicos que garanticen los derechos de la Religión"24.

Como se ha visto, otro elemento recurrente en las declaraciones de monseñor Builes, y que mencionará en sus pastorales, fue insistirles a sus fieles que era necesario evitar que las reformas liberales llevaran al país por los caminos de las revoluciones rusa o mexicana; o peor aún a una guerra civil como la que ocurría por esos años en España. Esta idea la desarrollaría durante los años en que en Colombia se experimentaban las reformas de la Revolución en Marcha, lideradas por el presidente liberal Alfonso López Pumarejo (1934-1936). Leamos en palabras del propio Builes cuál era su argumentación en este sentido:

En la Pastoral de cuaresma del año de 1926 os hemos hablado del peligro socialista que comenzando en Rusia, se viene extendiendo de manera alarmante por todo el mundo sembrando el ateísmo, la irreligión y el exterminio, y preparando días de horrible dolor para la humanidad entera, que en este momento se observa en México y España martirizados, en los países amarillos y en las naciones hispanoamericanas que hierven en continuas revoluciones [...] $\mathrm{Y}$ en nuestra amada patria no ha caído la semilla en campo ingrato; al contrario, es tierra muy fértil para tan malas yerbas ${ }^{25}$.

$\mathrm{Al}$ año siguiente de escrita esta pastoral, en el contexto de la reforma constitucional planteada por los liberales y que tenía por objeto, entre otros fines, disminuir el poder de la Iglesia, Builes continúa con su argumentación frente a lo ocurrido en España. Para él, de concretarse dicha reforma constitucional los radicales ganarían y la irreligiosidad invadiría el país. Como lo hicieron en "[...] Francia, durante la Revolución, en Rusia hace dos lustros, en México hace cinco años y en España hace

\footnotetext{
${ }^{23}$ Rafael Tamayo asegura que para este periodo se pasó de una escatología centrada en el infierno, la resignación y el martirio a una más centrada en el castigo: "A partir de la década de 1930 y hasta finales de la década de 1950, un segundo momento se hace evidente, en el que predominan los discursos de castigo y condena escatológica. En primera instancia, el liberalismo y luego, el socialismo son señalados como infernales. En las homilías, las pastorales, las catequesis y otras formas discursivas, el purgatorio y el infierno se hacen más frecuentes y más detallados. Tamayo Franco, Rafael. "Los imaginarios del purgatorio y el infierno durante la primera mitad del siglo XX en Colombia, entre la política y la religión”. Ponencia presentada en el XVII Congreso Colombiano... Op. Cit. p. 12.

${ }^{24}$ Builes, Miguel Ángel. "El liberalismo” en Cartas Pastorales... Op. Cit., p. 228.

${ }^{25}$ Builes, Miguel Ángel. "La rebelión-la inmoralidad”, febrero 2 de 1932, en Cartas Pastorales... Op. Cit., pp. 230-231.
} 
sólo uno [...]"26. En esta pastoral, su lenguaje es apocalíptico e invita a una defensa beligerante del catolicismo:

[...] En estos mismos momentos centellean como lenguas de fuego infernal, amenazantes y terribles, las espadas enemigas en todos los frentes, en la cátedra, en la tribuna, en los congresos, en las asambleas, en los periódicos, en los panfletos y hojas volantes, en convenciones y en proyectos de Constitución nacional, con lo que intentan derrocar a Cristo de su trono, para ellos levantarse el suyo sobre las ruinas, también nuestra palabra como espada y nuestra pluma como saeta han de flamear y clavarse en el propio corazón del monstruo que es el error, que es la herejía, aunque choquen contra la enemiga lanza y se rompan en mil pedazos, con tal de defender los derechos de Dios y de su Iglesia, hoy más que nunca odiada y perseguida.

No es la Iglesia la que provoca esta guerra: son nuestros enemigos quienes la llevan a la arena del combate, dice Pío X; no somos nosotros tampoco quienes hayamos de rehuir la lid: somos los jefes de la Iglesia militante y debemos luchar hasta lograr el triunfo, o caer como cumple a los intrépidos defensores de la $\mathrm{Fe}^{27}$.

Un lenguaje grandilocuente que podría ser entendido como el propio de un ortodoxo defendiendo su fe y que muy probablemente en un escenario menos bélico se podría leer solo como un discurso incendiario, pero esta no era la situación de Colombia. Por el contrario, el argumento de mostrar al liberalismo como enemigo de la Iglesia pudo haber sido uno de los mayores estímulos a la hora del combate partidista y que le trajo al país una de sus etapas más violentas a finales de la década de 1940 .

Miguel Zapata Restrepo, quien tuvo la oportunidad de entrevistarlo varias veces, escribe que la personalidad de este jerarca eclesiástico era incendiaria, dogmática y fuera de tiempo; que sus pastorales eran esperadas por amigos y enemigos para fustigar al adversario: decía lo que otros obispos pensaban pero que no eran capaces de expresar. Así lo describe Zapata Restrepo:

El detalle del enjuiciamiento sobre una pretendida persecución, demostraba que Builes vivía aún en las postrimerías del siglo XIX. No intuyó el advenimiento de una época nueva y dinámica en la cual era indispensable convivir con todos los matices ideológicos. Enarbolaba el maniqueísmo al tratar de dividir entre buenos y malos a los colombianos. En vez de buscar el diálogo, apelaba al báculo para golpear inmisericordemente a los que no acataban sus expresiones dogmáticas $[\ldots]$

Defendía el Concordato cual si fuera verdad revelada, sin meditar en la conveniencia de suaves y oportunas modificaciones [...] Proclamaba oír misa por decreto y comulgar por ley ${ }^{28}$.

\footnotetext{
${ }^{26}$ Builes, Miguel Ángel. "Las campañas contra Dios y la Iglesia”, enero 6 de 1933, en Cartas Pastorales... Op. Cit., p. 243.

${ }^{27}$ Ibid., p. 242.

${ }^{28}$ Zapata Restrepo, Miguel. La Mitra Azul... Op. Cit., p. 192.
} 
La respuesta por parte de los liberales hacia Builes también fue intransigente. Zapata Restrepo la relata de la siguiente manera:

Los liberales no estaban dispuestos a soportar que un obispo se interpusiera en el camino de la consolidación que habría de recorrer su partido. Preparaban elecciones con violencia y con fraude. Instalaban tanques de garrapaticidad (veneno para garrapatas) para bañar a los conservadores que se atrevían a llegar hasta las mesas de votación aglomeradas en la plaza de ferias de Medellín. Se adiestraban para copar registros donde ellos se hacían convenientemente. En consecuencia, no iban a transigir con la actitud de Miguel Ángel Builes.

Lo odiaron frenéticamente; se echó tierra sobre la obra misional que venía realizando; se le exhibió ante la faz de la nación como un sectario, olvidado de su rango episcopal. Se convirtió en un personaje de leyenda, lo cual debió complacerle en la intimidad. Sentiría profunda fruición, goce incontenible, cuando lo mencionaban como jefe del partido conservador ${ }^{29}$.

En este ambiente concurrieron las elecciones de 1936, después de una fuerte arremetida de los liberales en contra de la Iglesia y de una de sus figuras más representativas, el Obispo Coadjutor de Bogotá Juan Manuel González Arbeláez, que como se recordará había sido designado como posible sucesor del Primado Arzobispal, pero que por su intransigencia y cercanía a las ideas fascistas fue expulsado del país más adelante, en 1944. Los acontecimientos ocurridos en 1935, como consecuencia de la Reforma Constitucional, pusieron en la picota pública a monseñor González. El único obispo que asumió su defensa fue monseñor Builes, aunque no lo hizo inmediatamente como lo esperaban los liberales. No obstante, en 1936 sus críticas al liberalismo arreciaron y la pastoral de este año fue una de las más divulgadas en los periódicos nacionales y de provincia, el título de esta pastoral era elocuente: Los atentados de la masonería. En clara alusión a que todos los liberales son masones y por lo tanto enemigos de la Iglesia:

Se acerca el tiempo de cuaresma, tiempo de penitencia y de oración para los hijos de la Iglesia: penitencia de sus pecados y oración para implorar la misericordia de Dios sobre Colombia, esta Patria querida, que está para hundirse por culpa de sus propios hijos, en el horrendo abismo en que se revuelven desesperados Rusia y México, víctimas del comunismo y de la masonería [...]

Estamos en plena persecución legal, aunque con detestable hipocresía protesten religiosidad y respeto a la Iglesia los que la llevan al desastre y los que escriben en la prensa anticristiana $[\ldots]$

En muchas de nuestras pastorales sobre el liberalismo os hemos expuesto sucintamente las teorías de los enemigos de la Iglesia, las prácticas abominables que en el pasado han llevado a cabo y nuestros temores para el porvenir de la religión en nuestra patria. Los hechos ocurridos en estos seis últimos años y de manera especial, la vista del cuadro sombrío que representa en este momento nuestra Patria, demuestran a las claras que no eran infundados esos temores ${ }^{30}$.

\footnotetext{
${ }^{29}$ Ibid., p. 197.

${ }^{30}$ Builes, Miguel Ángel. "Los atentados de la masonería”, febrero 11 de 1936, en Cartas Pastorales... Op. Cit., pp. 307-312.
} 
Después de este recuento, Builes denuncia las persecuciones de que está siendo víctima el clero en general. Según él, durante el año de 1935, hubo actos sacrílegos en las ciudades de Cartagena, Medellín y Bogotá, y en algunos municipios del departamento de Bolívar. La blasfemia y el irrespeto a los párrocos, según este obispo, alcanzaron límites insospechados. En estas afirmaciones se perciben ciertas generalidades que no están sustentadas, pero que dichas por un obispo pudieron haber ocasionado que muchos feligreses y curas las tomasen en serio y de esta forma se estaba contribuyendo a generar un ambiente de "persecución religiosa". No obstante, en estas denuncias, un tanto superficiales, su principal crítica y más argumentada estuvo orientada a la reforma constitucional, que él consideraba atea; particularmente en lo concerniente a la educación. No contentos con agitarse ellos en ese ambiente de irreligión y de impiedad y
hacer propaganda de sus ideas y sentimientos anticristianos entre las personas
de mayor edad, quieren envenenar la sociedad en sus cimientos, pervirtiendo
la niñez, y contra ella enfilan todos los ejércitos y se enderezan todas las armas
masónicas con el fin de que las generaciones de mañana vivan lejos de la cruz,
y olvidados del Cielo, se levanten en la impiedad [...]

Recientes están las declaraciones de la asamblea de los Directores de educación habida en Bogotá, que no se quedaron en los anaqueles, sino que se tradujeron en ruda realidad masónica con el Decreto $\mathrm{n}^{\circ} 1.283$ de la Presidencia de la República en que se aprueban los planes masónicos sobre educación, y con el Decreto del Ministerio del 22 de julio de 1935 en que lanzan sus programas, saturados del laicismo, de naturalismo y de espíritu irreligioso [...]

Arrojada la Iglesia de la enseñanza, será ya más fácil prescindir de la enseñanza de la religión católica, o enseñar los errores del comunismo y del sovietismo que aspiran a adueñarse del mundo, estableciendo el ateísmo universal ${ }^{31}$.

Monseñor Builes en su intención de mostrar una Iglesia compacta, cita la pastoral Colectiva del Episcopado Colombiano (1935), referente a la educación, en la cual los jerarcas subrayaban los siguientes puntos: 1) una educación impartida y controlada por el Estado no es justo pues viola el derecho natural y va en contra de la libertad de enseñanza; 2) los programas de gobierno en lo referente a la educación están basados en un espíritu naturalista y laico; 3) las disposiciones de la reforma constitucional desconocen el Concordato vigente que obliga al Estado a que la educación esté dirigida y organizada según las disposiciones de la religión católica. Después de esta referencia episcopal, insiste en que la propuesta de coeducación o enseñanza mixta en instituciones educativas va en contra de la moral católica: "La coeducación de los dos sexos, claramente reprobada como nociva por el Sumo Pontífice, y condenada por los funestos resultados que ha producido, constituye uno de los postulados actuales de los enemigos de la Iglesia en nuestra Patria" 32 .

\footnotetext{
${ }^{31}$ Ibid., pp. 319-321.

${ }^{32}$ Ibid., p. 322.
} 
Ahora bien, las pastorales que escribió Builes durante estos años, hasta 1943, abordaron los mismos temas que venía tratando en torno al liberalismo ateo y masón, al comunismo irreligioso y a los peligros de vida corrompida de las ciudades. En la pastoral del 17 de marzo de 1943 y con motivo de la persecución de que estaba siendo objeto el obispo Juan Manuel González Arbeláez, Builes hizo unas breves referencias a esta situación. En este sentido, los sectores intransigentes de la época esperaban que Builes fuera más radical en la defensa de su "copartidario". Al respecto Miguel Zapata Restrepo considera que Builes con su silencio estaba actuando estratégicamente pues quienes decían apoyarlo, en el fondo no querían ponerse en evidencia ante las autoridades civiles y eclesiásticas que habían decidido presionar al Vaticano para que González Arbeláez saliera del país, como en efecto ocurrió en 1944.

En el año de 1945, con motivo de los acercamientos del clero bogotano al gobierno liberal de Alfonso López Pumarejo por medio del órgano informativo de la curia, Builes decide en su pastoral del 30 de enero distanciarse de esta postura y recordar una vez más que el liberalismo es pecado. “[...] el liberalismo actual, en sus procedimientos es más anticristiano que en los tiempos anteriores [...]"33. El paroxismo de Builes en contra del liberalismo llega a tal punto que el 20 de diciembre del mismo año decide decretar que para poder ingresar a los seminarios de su Diócesis es necesario que los aspirantes abjuren del liberalismo, una especie de preámbulo que anunciaba premonitoriamente la futura guerra bipartidista:

Como consecuencia de estas enseñanzas y para que al santuario no lleguen con el cargo de sacrificadores del cuerpo y de la sangre de Cristo, como predicadores de su evangelio, en una palabra, como obreros en la viña del Señor, los que estén mancillados con la lepra del liberalismo, queremos restablecer la prescripción [...] según la cual todo seminarista que venga por primera vez a nuestro seminario conciliar, lo mismo que a nuestro seminario de misiones, ha de formular su protesta formal contra el liberalismo, como lo hacen los subdiáconos, los neopresbíteros contra el modernismo, ante nosotros o nuestro delegado, poniendo sus manos sobre los santos evangelios ${ }^{34}$.

En el contexto en el cual Builes obliga a sus seminaristas a renegar del liberalismo, la violencia en contra de los liberales está comenzando a acrecentarse en los campos; con el cambio de gobierno adquiere una radicalidad inusitada. El nuevo gobierno conservador de Mariano Ospina Pérez (1946-1950), a pesar de su propuesta de Unidad Nacional, entró en una confrontación directa con los sectores radicales del liberalismo, liderados por Jorge Eliécer Gaitán. A pesar del discurso incendiario de Builes, Miguel Zapata Restrepo considera que este no contribuyó a la violencia. En este texto no comparte dicha apreciación, pues según lo analizado, la relación religiónpolítica, en épocas de violencia, sí cumple una función de justificar la desaparición del adversario, en este caso de los liberales, ya que estos son identificados como enemigos

\footnotetext{
${ }^{33}$ Builes, Miguel Ángel. "La educación cristiana”, enero 30 de 1945, en Cartas Pastorales... Op. Cit., p. 30.

${ }^{34}$ Builes, Miguel Ángel. "Algunos errores de nuestros tiempos", diciembre 20 de 1945, en Cartas Pastorales... Op. Cit., p. 42.
} 
de la religión ${ }^{35}$. Aunque como ya se ha dicho los liberales no se consideraban a sí mismos como ateos. En el caso de los feligreses, Zapata Restrepo relata cómo Builes también los hacía jurar para que defendieran la religión de cualquier ataque liberal ${ }^{36}$. Igualmente, considera que los conservadores no tomaban en serio estas declaraciones: "No se detuvieron a pensar si el liberal del cercano barbecho vivía en permanente pecado mortal. No consideraron que había que extrañarlo de su aldea o del caserío por motivos de asepsia banderiza. Al menos en cuanto a los fieles correspondía, pastorales de ese tipo tuvieron más un concepto peyorativo que una orden" "37. A pesar de esta defensa resulta difícil creer que durante los períodos de violencia extrema, los campesinos organizados en autodefensas o más adelante en fuerzas oficiales del gobierno conservador, pudieran hacer esta distinción. Más aún, cuando en las elecciones de 1946 clérigos como monseñor Builes orienta sobre el "Deber de los electores" (27 de abril):

El próximo 5 de mayo tendrán lugar las elecciones para presidente de la república.

Es deber de los católicos votar por un candidato que garantice los derechos de la iglesia y es obligación de los obispos recordar a los fieles este doble deber: $1^{\circ} \mathrm{El}$ de dar su voto, pues un voto puede decidir le elección; $2^{\circ} \mathrm{El}$ de darlo por un candidato que garantice los derechos y prerrogativas de la Iglesia y de la Religión $[\ldots]$

Para el buen éxito de las elecciones del próximo domingo 5 de mayo disponemos lo siguiente:

$1^{\circ}$ Exciten los venerables párrocos a todos los fieles a que salgan a votar [...]

$2^{\circ}$ Hagan ver a los católicos que deben cumplir su deber con la mayor cordura $[\ldots]$

$3^{\circ}$ Diríjanse al cielo fervorosas oraciones y cuantos sacrificios puedan practicarse, pidiendo a Dios Nuestro Señor el triunfo de un verdadero candidato católico $[\ldots]$

$5^{\circ}$ En todas las parroquias, antes de la primera misa, háganse fervorosas rogativas, llevando en procesión por la plaza una imagen de la Virgen, cantando en las letanías mayores, como en los días de las rogaciones [...]

La presente circular será leída y rápidamente comentada in omni patienta et sancta prudentia, desde el primer viernes, si llegare a tiempo, y en las misas que se celebren el domingo 5 de mayo en todas las iglesias y capillas de nuestra diócesis ${ }^{38}$.

\footnotetext{
${ }^{35}$ Vale la pena recordar que en este período y sobre todo tras la muerte de Gaitán, el 9 de abril de 1948 se dio de una de las guerras civiles más violentas del país que dejó un saldo de más de 200.000 muertos. En esa ocasión la mayoría de los símbolos del poder oficial y clerical en Bogotá (y otras ciudades del país) fueron atacados o quemados por las hordas de liberales que venían en ellos la representación de la exclusión y la represión oficial.

${ }^{36}$ Zapata Restrepo, Miguel. La Mitra Azul... Op. Cit., p. 332.

${ }^{37}$ Ibid., p. 334.

${ }^{38}$ Builes, Miguel Ángel. “Deberes de los electores”, abril 27 de 1946, en Cartas Pastorales... Op. Cit., p. 52.
} 
Esta orientación divulgada masivamente en la mayoría de los periódicos del país pudo haber sido producto de la certeza que tenían los conservadores de volver al poder, después de 16 años de dominio liberal. Esto como consecuencia de la división del liberalismo que para las elecciones de 1946 contaba con dos candidatos presidenciales: Gabriel Turbay y Jorge Eliécer Gaitán.

No obstante, la imagen de Builes como un político aguerrido, su labor pastoral es reivindicada por otros biógrafos, sobresalen de estos, el intelectual conservador Jaime Sanin Echeverri, quien muestra a monseñor Builes como un clérigo comprometido con sus funciones sacramentales. De esta función destaca la creación en su diócesis de cuatro organizaciones religiosas: el Seminario de Misiones Extranjeras de Yarumal (1927); las comunidades de las Misioneras de Santa Teresita del Niño Jesús (1927), de las Misioneras Teresitas Contemplativas (1929) y las hijas de Nuestra Señora de las Misericordias (1951). Para este biógrafo, el trabajo misional de Builes fue producto de su origen y formación rural, ya que sus padres eran trabajadores de la tierra y él mismo lo fue durante sus primeros años de adolescencia. Además, el Seminario Menor de la Diócesis de Antioquia (regentado por la comunidad de eudistas) donde se ordenó, también tenía como vocación el trabajo rural. La misma que Builes le dio al seminario que él fundó años después en Yarumal (pequeño pueblo de su diócesis). Así lo recuerda uno de sus discípulos más prominentes pero no consagrados, el presidente de Colombia Belisario Betancur (1982-1986), quien se había educado en dicho seminario:

Quizá la clase que más me interesaba era la de agricultura práctica, porque todos los seminaristas y los curas profesores, y monseñor Builes, todos éramos agricultores. Yo venía de echar azadón, de verdad y por necesidad; y consideraba un poco indignante el tener que hacerlo [...] años después supe por qué estas clases, idea del propio monseñor Builes, eran consideradas por él tan importantes como la enseñanza tomista. Lo que monseñor Builes quería formar era curas misioneros, colonizadores, abridores de monte; y, con justa razón creía que sólo un sacerdote que supiera a fondo la agricultura, podía hablar con los campesinos de tú a tú [...] Así, pues, las verduras que comíamos en el seminario, las papas, las arracachas, los plátanos, las yucas, eran cultivados por nosotros mismos ${ }^{39}$.

En una entrevista que Belisario Betancur realizó en 1946 a Builes fue mucho más contunde en su posición frente a él, pues lo mostraba como un campesino que había logrado llegar al solio episcopal gracias a su carisma y trabajo misional: "El prelado antes que todo es un campesino elevado a la divinidad episcopal en gracia de su saber y dignidad" 40 .

\section{Conclusión}

Después de este breve recuento sobre los escritos escatológicos y políticos de monseñor Builes que evidencian su coherencia y beligerancia, se puede concluir que el discurso del clero rural, del cual él fue uno de los más representativos, es mucho más intransigente que el utilizado por la jerarquía eclesiástica bogotana. Es decir,

\footnotetext{
${ }^{39}$ Sanín Echeverri, Jaime. El Obispo Builes (Medellín: Editora Géminis, 1998), p. 9.

${ }^{40}$ Betancur, Belisario. Sábado (semanario), Bogotá, septiembre 28 de 1946. p.1.
} 
mientras el Arzobispo de Bogotá, Ismael Perdomo o el nuncio apostólico, buscaban mantener buenas relaciones con los gobiernos liberales, personajes como monseñor Builes, gracias a su liderazgo regional, lograban polarizar la sociedad. Esta situación explicaría, hasta cierto punto, la radicalidad del conflicto en las zonas rurales durante la violencia de mediados del siglo XX en Colombia. Además, pone en evidencia cómo la corriente intransigente decimonónica, en un país político como la Colombia de la primera mitad del siglo XX, se alió con los miembros del Partido Conservador para hacerle oposición a cualquier intento liberal de disminuir el poder clerical; aún más, dentro del programa del Partido Conservador, los primeros puntos doctrinales insisten en defender todos los principios católicos y el fuero del clero, tal vez por ello en Colombia no fue necesario crear un partido católico pues esta función la llevaban muy bien los conservadores. Por otro lado, a pesar de que los movimientos sociales y las ideas socialistas comenzaban a calar, para conservadores y clérigos los verdaderos enemigos eran los liberales, será después de mediados del siglo XX, donde la ideología anticomunista unificará a ambos partidos con el beneplácito de un sector del clero.

La importancia del clero rural, en la mediación cultural y política que la Iglesia realizaba, fue fundamental para mantener una sociedad compacta. También, al ser la institución vigilante de la moral y del comportamiento de los colombianos logró conservar una sociedad tradicionalista. El origen rural de los sectores más intransigentes de la Iglesia, fue determinante en la defensa de las tradiciones rurales; sobre todo en regiones, que hasta los años sesenta, todavía vivían a "son de campana", pero que comenzaban a desplazar a un porcentaje importante de su población a las ciudades, la cual, no obstante esa migración, no abandonó sus tradiciones o creencias, de ahí que la ciudad se convirtió en un híbrido entre dichas tradiciones y lo urbano. Monseñor Builes no tenía razón, la ciudad no se comió al campesino, este la adaptó a sus necesidades y creencias; además, comenzó, desde los años sesenta, a deambular por las otras tradiciones cristianas de origen carismático que le complementaron su catolicismo popular.

Vale la pena insistir que en este estudio no ha sido posible distanciarse con más radicalidad de la historiografía liberal anticlerical y su intento de desprestigiar a la institución eclesiástica o cuestionarle su incoherencia religiosa, desde una interpretación ideológica cargada de críticas intransigentes, porqué en Colombia no existe tal anticlericalismo y además porqué es evidente que en efecto hubo sectores de la institución eclesiástica que si se aprovecharon de su condición privilegiada para venderle a sus fieles la idea de que los liberales eran pecadores. Tal vez ese uso maniqueo de la religión logró contribuir a la violencia de esos años. Además, la corriente intransigente del catolicismo - establecida por el papa Pio IX en 1864 en el Syllabus- representada en la figura de Monseñor Builes, en Colombia se mantuvo hasta mediados del siglo XX, cuando el mundo se preparaba para la llegada de corrientes político-religiosas más modernas impulsadas por al papa León XIII desde finales del siglo XIX por medio de la Encíclica Rerum Novarum (1891), de ahí que la posición de Monseñor Builes ya no era la predominante, infortunadamente en la iglesia colombiana, al parecer, tampoco esta desapareció con la muerte de Builes en 1971. 
Por último, se podría aventurar con Miche Foucault que el discurso escatológico mezclado con la ideología política logra trascender en el creyente de forma más profunda. En ese sentido, las acciones políticas de los encargados de cuidar las almas de los fieles católicos adquieren una intensidad que todavía hoy no se ha estudiado con profundidad, dado que las investigaciones sobre la relación política-religión se han limitado a estudiar el accionar político de algunos clérigos y hasta ahora se empiezan a vislumbrar investigaciones que apuntan más al análisis teológico y antropológico de dicha relación y que podrían explicar más claramente sus implicaciones espirituales.

\section{Fuentes}

\section{Fuentes primarias}

\section{Publicaciones periódicas}

Sábado (semanario), 1946.

Libros

Builes, Miguel Ángel. Cartas Pastorales. 1940-1956. Medellín: Imprenta Editorial, 1957.

Sanín Echeverri, Jaime. El Obispo Builes. Medellín: Editora Géminis, 1998.

Uribe Uribe, Rafael. El liberalismo colombiano no es pecado. Bogotá: Planeta, 1995.

Zapata Restrepo, Miguel. La Mitra Azul. Miguel Ángel Builes: el hombre, el obispo, el caudillo. Medellín: Beta, 1973.

\section{Capítulos de libros}

Builes, Miguel Ángel. "Saludo en la toma de posesión de la Diócesis, el 22 de octubre de 1924, al venerable clero y a los fieles", en Cartas Pastorales. 1914-1939. Medellín: Imprenta Editorial, 1939.

\section{Fuentes secundarias}

\section{Libros}

Abel, Christopher. Política, Iglesia y Partidos en Colombia 1886-1955. Bogotá: FAES, Universidad Nacional de Colombia, 1987.

Figueroa S., Helwar H. Tradicionalismo, hispanismo y corporativismo. Una aproximación a las relaciones nos sanctas entre religión y política (1930-1952). Bogotá: Universidad de San Buenaventura, 2009. 
González, Fernán. Poderes enfrentados. Iglesia y Estado en Colombia. Bogotá: Cinep, 1997.

Grupo de Investigación Religión, Cultura y Sociedad (GIRCS). Historiografía sobre religión, cultura y sociedad en Colombia producida entre 1995 y el 2000. Medellín: Universidad Nacional de Colombia, 2001.

La Rosa, Michael. De la derecha a la izquierda. La Iglesia Católica en la Colombia contemporánea. Bogotá: Planeta, 2000.

Ordoñez, Francisco. Historia del cristianismo evangélico en Colombia. Medellín: Tipografía Unión, 1955.

Richard, Pablo. Morte das cristiandades e nascimento da Igreja. Análise histórica e interpretacao teológica na América Latina. Sao Pablo: Paulinas, 1984.

Roux, Rodolfo de. Una iglesia en estado de alerta. Bogotá, Guadalupe, 1983.

Toro Jaramillo, Iván Darío. El pensamiento de los católicos colombianos en el debate de la "crisis del medio siglo". Medellín: Luis Amigo, 2005.

\section{Capítulos de libros}

Arias, Ricardo. "La historiografía de la Iglesia católica en Colombia", en Bonnet, Diana y Maya, Luz Adriana (comp.), Balance y desafios de la historia de Colombia al inicio del siglo XXI. Bogotá: Universidad de los Andes, 2003.

Figueroa S., Helwar H. "Cambio de enemigo: de liberales a comunistas. Religión y política en Colombia, años cuarenta", en Bidegain Greising, Ana María y Demera, Juan Diego (comps.), Globalización y diversidad religiosa en Colombia. Bogotá: Universidad Nacional de Colombia, 2005.

Pérez Rivera, Eduardo. "El nacionalismo católico colombiano: un estilo de pensamiento (1870-1946)". En: Nación y nacionalismo en América Latina. Bogotá: CES-FLACSO, 2007.

Plata Quezada, William Elvis. "De las reformas liberales al triunfo del catolicismo intransigente e implantación del paradigma romanizador", en Bidegain, Ana María (comp.), Historia del cristianismo en Colombia: Corrientes y diversidad. Bogotá: Taurus, 2005.

Plata Quezada, William Elvis. "Entre la teología y las ciencias sociales. Tendencias de la historiografía de la Iglesia Católica en Colombia, en el contexto latinoamericano", en González, Andrés Eduardo (comp.), Diversidad y dinámicas del cristianismo en América Latina. Memorias del primer congreso internacional. Bogotá: Universidad de San Buenaventura, 2007. 


\section{Artículos en revista}

Cortés, José David. "Balance bibliográfico sobre la historia de la Iglesia católica en Colombia, 1945-1995”, en Historia Crítica, n. ${ }^{\circ}$ 12, 1996.

Cortés, José David. "Balance historiográfico sobre las relaciones Estado-Iglesia desde la Independencia hasta finales del siglo XIX", en Historia y sociedad, n. ${ }^{\circ} 18,2010$.

Figueroa S., Helwar H. "Historiografía sobre el protestantismo en Colombia. Un estado del arte, 1940-2009", en Anuario Colombiano de Historia Social y de la Cultura, n. ${ }^{\circ} 37,2010$.

Tamayo Franco, Rafael. "Los imaginarios del purgatorio y el infierno durante la primera mitad del siglo XX en Colombia, entre la política y la religión". Ponencia presentada en el XVII Congreso Colombiano de Historia, Bogotá, octubre 5-10 de 2015.

\section{Tesis}

Tamayo Franco, Rafael. Los discursos de la escatología católica en los imaginarios religiosos y políticos, Colombia 1887-1965, (Tesis doctoral), Universidad Nacional de Colombia, 2015.

Urrego, Miguel Ángel. 1990. La Creación de un Orden Teocrático durante la Regeneración, (tesis maestría), Universidad Nacional de Colombia, 1990.

\section{Publicaciones en internet}

Arias, Ricardo. Estado laico y catolicismo integral en Colombia. La reforma religiosa de López Pumarejo. Red iberoamericana los las libertades laicas, 2005, http://www. lablaa.org/blaavirtual/letra-r/rhcritica/arias2.htm\#_ftn1. 